\section{FN5 (continued)}

further potential areas to drive campus policy to raise awareness of health promotion.

Conclusions and Implications: A student run audit is an effective way to assess the campus environment, enhance students' perceptions and awareness of the campus environment and have them report back to peers. Having stakeholders assess the environment allows them to become active in policy change.

Funding: USDA

\section{FN6 iCook 4-H: Using Mapping of Community Capitals Following a 2-Year iCook Program}

Melissa D. Olfert,DrPH, MS, RDN, melissa.olfert@mail. wvu.edu, West Virginia University, G016 Ag Sc Building, Morgantown, WV 26506; S. E. Colby, PhD, RDN, University of Tennessee-Knoxville; L. Franzen-Castle, PhD, $R D N$, University of Nebraska-Lincoln;

K. K. Kattlemann, PhD, RDN, South Dakota State

University; B. Baker, MS, University of Maine;

A. White, PhD, RDN

Objective: To evaluate participants' perceived ripple effect of a 2 year iCook 4-H multistate intervention program on individual, family and their community with youth (Y) and adult (A) pairs (dyads).

Design, Setting, and Participants: Treatment participants, $\mathrm{n}=70$ (34\% of total sample); (35 A, $35 \mathrm{Y}$, ages 1112 years) participated across 5 states (ME, NE, SD, TN, WV) in 10 groups.

Outcome Measures and Analysis: Ripple Effect Mapping (REM) evaluation tool was used to elicit reflections from impact of program on 7 Community Capitals Framework (CCF) (human, social, cultural, built, financial, natural, political). Three main themes, cooking, eating and playing together were evaluated after a 24-month childhood obestity intervention. Group dyads responded to leader driven dialogue about ways iCook affected individual, family and/or community through open-ended questions: what are people doing differently as a result of iCook; who has benefited and how are there changes in the way community groups and institutions do things as a result of iCook? Dialogues were recorded and evaluated thematically using grounded theory.

Results: Dyads reported adopting new behaviors such as an increase in physical activity, increased frequency of trying new foods and improved communication skills as well as increased harmony within family units identifying capitals such as human, social and natural predominately. Positive family behavior change affected all capitals of the CCF which resulting in amplified participants' awareness of the importance of connecting within dyad; building new relationships, some of which formed during community volunteering.

Conclusions and Implications: Findings support the need for youth obesity prevention programs, such as iCook, that positively intersect and affect self, families and communities.

Funding: USDA

\section{FN7 Recruitment Effectiveness and Barriers for a Clinical Site Intervention to Track Nutrition Application Usage}

Melissa D. Olfert,DrPH, MS, RDN, melissa.olfert@mail. wvu.edu, West Virginia University, G016 Ag Sc Building, Morgantown, WV 26506; M. L. Barr, BS; A. Baus, PhD; T. Taggerty, MD, WVU Family Practice; M. Weimer, MD, Valley Health System; D. Doyle, MD, Cabin Creak Health; M. A. Maurer, DO, CAMC Family Practice; J. Cochran, NP, $P h D$, Robert C. Byrd Clinic; T. Hendershot, MD, Coplin Memorial Community Health; S. Hodder, MD, WV Clinical Translational Science Institute

Objective: To recruit from rural settings (environment limitations) capturing lessons learned for the Project Better Health (PBH) Study in West Virginia, a 12-week feasibility study to implement a nutrition tracking application into primary care clinics.

Design, Setting, and Participants: This project required multiple layers of recruitment including coordinators, primary care physicians (providers), and patients requiring three time points of data collection (baseline, 4-week, and 12-week height, weight, blood pressure and surveys collected). A survey collected feedback from two phases of recruitment: phase 1 was recruitment of rural site investigators and coordinators; and phase 2 was recruitment of providers and patients at seven clinical sites rom state coordinators and practice based research network (PBRN) partners.

Outcome Measures and Analysis: Recruitment successes for phase 1 were using the PBRN members and having investigators speak at PBRN site tours. Barriers were information not pertaining to a specific location or not streamlined/easy to understand information, and finding providers with existing CITI training. For phase 2, successes were finding providers enthusiastic, previous experience with PBRN and supportive adminstration. Barriers were inability to post flyers and fact sheets to advertise, using sites where providers were "nudged" or "told" to be a part of the project, left the site halfhearted.

Results: Seven rural clinical sites, 10 providers ( 4 male, 7 female), and 49 patients were recruited. Patient demographics include a predominately Caucasian population with $20.4 \%$ male, $79.6 \%$ female at an average of 43.3 years of age. Health conditions of patient population include hypertension (22), diabetes (11), and sleep apnea (9).

Conclusions and Implications: Recruitment in rural areas can be overcome if identifying clinics and providers with relationships or existing partnerships.

Funding: West Virgina Clinical Translational Science Institute

\section{FN8 Shortening Pittsburgh Sleep Quality Index Survey Using Factor Analysis}

Melissa D. Olfert,DrPH, MS, RDN, melissa.olfert@mail. wvu.edu, West Virginia University, G016 Ag Sc Building, Morgantown, WV 26506; I. Holaskova, PhD; M. L. Barr, BS; Z. Wenjun, PhD, University of Tennessee-Knoxville; 
FN8 (continued)

J. Morrell, PhD, University of New Hampshire;

S. E. Colby, PhD, University of Tennessee-Knoxville

Objective: To conduct an exploratory factor analysis to reduce a 19-item survey to a shorter but still effective tool of the Pittsburgh Quality Sleep Index, a validated survey to assess sleep habits, define healthy sleepers from poor or clinically problematic sleepers (sleep policy is non-existent).

Design, Setting, and Participants: Sleep data was collected from 236 college-age students during spring 2015 as a first step analysis.

Outcome Measured and Analysis: A factor analysis using a loading cut-off of 0.60 from 236 subjects, with a total of 7 latent factors, was examined and promax rotation was conducted to allow for correlated variables.

Results: The 7 factors explained $70.5 \%$ of the variability. The first factor related to sleep quantity and the second factor related to sleep latency with both factors having two questions. Factor three, five and six related to sleep disturbances, each having one question about breathing uncomfortably, being too hot, and waking up in the middle of the night respectively. The fourth and seventh factors centered on sleep quality and trouble engaging in daily activities and overall sleep quality. Next steps will be to repeat the analysis with larger sample size $(\mathrm{n} \sim 1000)$, then only use the questions related to identified factors and repeat the factor analyses to see if the shortened version of the survey reflects the same factors identified in the original 19-item questionnaire. Then the overall scores for both the 19item questionnaire and the shortened survey (with adjustments made for scale) will be compared.

Conclusions and Implications: Lengthy surveys over-burden study participants increasing inaccuracies if participants rush or omit information to finish. Shortening existing validated surveys may prove beneficial in limiting participant burden.

Funding: USDA

\section{FN9 Nutrition Intervention to Profile} Microbiome and Behaviors in Young Adults at Risk for Metabolic Syndrome: FRUVEDomic Pilot Study

Melissa D. Olfert,DrPH, MS, RDN, melissa.olfert@mail. wvu.edu, West Virginia University, G016 Ag Sc Building, Morgantown, WV 26506; C. Cuff, PhD; A. Cockburn, PhD; M. Olfert, PhD; J. W. McFadden, PhD; M. Downes, PhD;

P. J. Murray, PhD; I. Holaskova, PhD; M. L. Barr, BS;

S. E. Colby, $P h D$, University of Tennessee-Knoxville; J. Morrell, PhD, University of New Hampshire

Objective: Investigate the effects of an eight-week nutritional intervention on the microbiome and behaviors of "at risk" young adults (18-28 years) for metabolic syndrome (MetS).

Design, Setting, and Participants: Thirsty-six subjects were recruited at West Virginia University and randomized into one of three intervention groups; "Fruved" (50\% fruit and vegetable); "Fruved+LowCHO" (low refined carbohydrate); and "Fruved+LowFat" (low fat).

Outcome Measures and Analysis: Stool samples and a 200-item lifestyle survey were collected pre and post intervention. Alterations in the fecal microbiome were assessed using high throughput sequencing of the V3-V4 regions of the 16S rRNA gene (Illumina MiSeq). MetS severity was measured using a Z-score from survey data.

Results: All individuals significantly decreased empty calories ( $p<0.0001)$ and increased fiber $(p<0.001)$ and cups of fruit and vegetable $(\mathrm{p}<0.0001)$ after 8 weeks, with no differences between groups. improvements in weight, waist circumference, systolic blood pressure and body fat were seen in all individuals $(\mathrm{p}<0.05, \mathrm{p}<0.0001, \mathrm{p}<0.01$ and $\mathrm{p}<0.05$ respectively). Additionally, insulin sensitivity improved $(\mathrm{p}<0.05)$ and total cholesterol decreased $(\mathrm{p}<0.05)$. A positive relationship of MetS Z-score and proportion of bacteroidetes was detected $(\mathrm{p}=0.03)$, regardless of time ( $\mathrm{p}=0.87$ ), utilizing repeated measures ANOVA. The effects of MetS Z-score on firmicutes and the ratio of the firmicutes to bacteroidetes were approaching significance with negative slopes $(\mathrm{p}=0.051$ and 0.07 respectively), without the significant time effect.

Conclusions and Implications: Healthy diet improves cardiovascular health in all individuals. Specific profiles of inflammation in phylum level microbiota for those considered "at-risk" of MetS were identified. Identifying markers among "at risk" individuals may help direct precision medicine and generate individually, tailored nutrition prescription and possibly policies in their environments.

Funding: West Virgina Clinical Translational Science Institute

\section{FN10 Online Marketplace for "Made in Maui" Value-Added Products}

Cynthia Reeves, PhD, MPH, reevesc@hawaii.edu, University of Hawaii at Manoa, 310 Kaahumanu Avenue, Building 214, Kahului, HI 96732

Objective: A single-day, festival was broadened to include a 24/7 web-based marketing platform for local agricultural value-added producers in Maui County.

Target Audience: Farmers and entrepreneurs creating value-added products in Maui County.

Theory, Prior Research, Rationale: The "Made in Maui" event just completed its second year of implementation. This is a one day event and opportunity for local farmers and entrepreneurs to show and sell their valueadded products to wholesalers, visitors and consumers. Unfortunately, the webpage for this event only provides a static listing of the vendors and their products. Once the event is over, there is no mechanism for ongoing marketing. Thus, the need for a database driven, vendor marketing website was identified.

Description: The University of Hawaii Maui County Cooperative Extension office partnered with the County Office of Economic Development and the Chamber of Commerce to develop an online marketing hub for vendors of "Made in Maui" agricultural value-added products.

Continued on page S146 